\title{
Correction to: Emergence and Expansion of Preclassical Mechanics
}

Rivka Feldhay, Jürgen Renn, Matthias Schemmel, and Matteo Valleriani

\section{Correction to:}

R. Feldhay et al. (eds.), Emergence and Expansion

of Preclassical Mechanics, Boston Studies

in the Philosophy and History of Science 270,

https://doi.org/10.1007/978-3-319-90345-3

The book was inadvertently published with wrong volume number as 333 . The same has now been corrected throughout the book. The correct volume number is 270 . 